\title{
Editorial Número Especial
}

\section{A PSICOLOGIA SÓCIO-HISTÓRICA: UM REFERENCIAL DE ANÁLISE E SUPERAÇÃO DA DESIGUALDADE SOCIAL LA PSICOLOGÍA SOCIO-HISTÓRICA: UN REFERENCIAL DE ANÁLISIS Y SUPERACIÓN DE LA DESIGUALDAD SOCIAL THE SOCIO-HISTORICAL PSYCHOLOGY: A THEORETICAL FRAMEWORK ANALYSIS AND OVERCOMING OF THE SOCIAL INEQUALITY}

\begin{abstract}
"Em um de seus trabalhos de juventude ${ }^{1}$, Marx afirmou que se a psicologia desejasse tornar-se uma ciência realmente significativa, teria que aprender a ler o livro da história da indústria material, que contem 'as forças humanas essenciais', que é a encarnação concreta da psicologia humana".
\end{abstract}

(Vigotski, A Modificação Socialista do Homem, p.117)

O presente número especial visa divulgar a produção do GT/ANPEPP A Psicologia Sociohistórica e o contexto brasileiro de desigualdade social, para abri-la ao debate com todos que buscam o aperfeiçoamento da práxis psicossocial de enfrentamento da desigualdade social.

Falar de psicologia sócio histórica, necessariamente remete a sua genial artífice brasileira, Silvia Lane, membro deste GT desde sua criação em 1994 até sua lastimável morte em 2006. Esta filósofa adotou a psicologia com a intenção de desideologizá-la, esforço que, segundo ela, valia a pena pelo potencial político dessa ciência, encoberto por teorias anti-historicistas e idealistas. Desde os anos 80 , ela e sua equipe foram elaborando, com clareza e conviç̧ão crescentes, o projeto de um psicologia social brasileira, compromissada com a superação da exploração, perpetrada pelas particularidades históricas da luta de classes em nossa sociedade, perversamente reproduzida e encoberta por mecanismos psicossociais que excluem do conhecimento psicológico o conhecimento da realidade social.

Desde a década de 1980, urgia, portanto, a superação dos referencias teóricos e metodológicos que isolavam o psiquismo da sociedade e da história. Como primeiro passo, então, Lane e sua equipe propuseram a adoção obrigatória por parte da psicologia de uma teoria social e escolhe a marxista, pela sua crítica à neutralidade científica e à concepção idealista e ahistórica de homem e sociedade. Também, porque esta teoria introduzia a suspeita em relação á concepção harmônica de sociedade, que sustentava a postura política da intervenção psicológica voltada à adaptação social. Quanto à teoria psicológica, buscou as referendadas nos mesmos pressupostos do materialismo-histórico e dialético. Depois de muitos estudos, passando por Politzer, Lefebrve, Le Ny, Escola de Frankfurt etc., encontraram os soviéticos, dentre eles, Leontiev e, depois, Vigotski (1896 - 1934).

Este último, entusiasta da arte que estudou direito, filosofia e história, interessou-se pela psicologia para melhor entender a fruição artística e a catarse, visando colaborar com a formação do homem novo da revolução socialista, já que estava inconformado com a situação mundial desta ciência na sua época. Aquele era um momento em que as principais escolas teóricas reduziam a psicologia a um único princípio explicativo (inconsciente, comportamento, reflexo condicionado, cognição), como se fossem excludentes uns aos outros. Assim, impõe-se a meta de construir "O Capital" da psicologia, criando conceitos como unidade de análise à semelhança da "mercadoria" - uma unidade mínima que preserva a as propriedades do todo -, um "coágulo concentrado" (expressão que ele extrai da obra de Gógol) das forças sociais e subjetivas do momento histórico em que se situa. Sua meta, portanto, significava operar um deslizamento metodológico dos conceitos psicológicos, promovendo o enraizamento deles na organização histórico-social e, dialeticamente, do social no psiquismo.

Tal giro teórico, só seria possível, segundo Vigotski, pela substituição do método positivista pelo método dialético, uma vez que este permitiria à psicologia trabalhar com duas categorias de realidade aparentemente irredutíveis: subjetividade e objetividade, como unidade de contrários. De outra forma, não seria possível entender como as relações sociais movidas por contradições, ao serem vivenciadas, singularizam-se como funções psicológicas em luta. Esta concepção levou Vigotski a recomendar que o 
psicológico devesse ser analisado como drama e como singularidade. Aqui reside uma das contribuições mais importantes de sua obra: demonstrar que as determinações sociais, embora constituintes da condição humana, não destroem a singularidade, a liberdade e a criação e que, portanto, o sujeito da necessidade estética, da criação e da liberdade não é subjugado, mas configurado socialmente.

A dialética abriu inúmeras possibilidades analíticas para aquele que se entusiasmou e se comprometeu com os ideais da revolução russa, mas que por isso mesmo prezava a liberdade de refletir e pesquisar para fazer da psicologia uma verdadeira ciência. Mesmo recusando-se a rotulá-la formalmente de marxista, Vigotski recheou a psicologia de citações recortadas da obra de Marx, Lenin e Engels, objetivando reconstruir a psicologia como ciência, por meio da introdução do método marxista.

Essa não ortodoxia em relação ao formalismo marxista da era stalinista fez com que a obra de Vigotski fosse proibida de circular em seu país. Em 1937, foram publicados 10.000 exemplares do folheto de E.I. Rudneva, "Vigotski distorções pedológicas", afirmando que a teoria de Vigotski tinha uma orientação antimarxista e que seus livros "causaram grandes danos à escola Soviética"2.

Foram os pressupostos e a maneira de trabalhar o marxismo na psicologia que levaram Silvia e sua equipe a estudar a obra desse genial pensador russo. Uma obra que, embora inacabada, abre horizontes à prática psicossocial com questões sociais e coletivas. Uma obra marxista, porém também espinosista, já que Espinosa era seu filosofo preferido, conforme ele mesmo afirmava. Uma obra que usufrui da arte e de outras áreas do conhecimento, por exemplo, a inspiração encontrada no método de interpretação cênica de Stanislaviski, utilizada para explicar que por trás de um discurso há sempre um subtexto afetivovolitivo, e na obra do linguista Paulham, para distinguir as duas dimensões do sentido: a singular e a social. Ele confrontou-se dialeticamente com os principais psicólogos da época: Lewin, Freud, Wundt, Piaget, Köhler, James, Stern, para citar alguns, seguindo seu intento de não eliminar os conceitos clássicos da psicologia, mas situá-los historicamente, superando suas dicotomias.

Vigotski procurou problematizar a psicologia de seu tempo e encontrar suas áreas de crescimento e de colaboração com o processo revolucionário e com o desenvolvimento humano. Lane e sua equipe inspiraram-se em sua teoria para configurar uma própria, comungando com a postura epitemológica vigotskiana de fidelidade epistemológica ao marxismo, mas sem fundamentalismos e ordodoxias, permitindo a ampliação de horizontes analíticos.

O conceito escolhido para nominar esta teoria foi a de psicologia sócio histórica, ao invés do comumente nome atribuído à escola russa liderada por Vigotski - histórico cultural. Lane considerou ser aquele o melhor conceito por julgar que a palavra social reforça a concepção marxista de sociedade atravessada pela luta de classes e a vigotskiana de materialidade e historicidade do fenômeno psicológico. Mas, ao denominar de sócio histórica a teoria, tinha também a intencionalidade de mostrar sua relação com a teoria vigotskiana, demarcando uma flexibilidade teórica ao construí-la à luz de pesquisas sobre nossa realidade, especialmente, as que demonstram de forma crucial a exploração e a dominação.

Coube-nos dar continuidade ao processo e buscar aprimorá-lo a partir do legado teórico vigotskiano e seu potencial marxiano, com o objetivo de construir ações e reflexões sobre o psicológico como questão social. Tais conhecimentos se fazem especialmente importantes no campo da assistência social, da saúde coletiva, das políticas públicas, dando suporte à ONGs e outras organizações coletivas que visem a autonomia e a participação social.

Neste número, apresentamos pesquisas e reflexões sobre a desigualdade, visando ações transformadoras no âmbito de competência que tradicionalmente caracteriza a Psicologia: a subjetividade. Todos os textos analisam a articulação entre subjetividade, desigualdade social e políticas públicas, referendados na obra de Vigotski e na interlocução com pensadores que lhe serviram de base, com destaque para Marx e Espinosa.

São 11 textos agrupados em dois conjuntos de preocupação, um composto de reflexões teóricometodológicas e outro de relatos de pesquisaintervenção. Além de garantir a representação de várias instituições, localizadas em diferentes regiões do Brasil, procurou-se garantir, na composição, uma variedade de interpretações da Psicologia SócioHistórica.

O primeiro bloco, teórico/metodológico, traz à discussão questões e categorias centrais pouco abordadas pela psicologia de base sócio-histórica, que permitem trabalhar as questões de desigualdade na dialética singular/social, subjetividade e objetividade, como o inconsciente, afetividade pública, transformação social/individual, arte e liberdade, bem como reflexões sobre a falsa cisão entre metodologia quantitativa e qualitativa e entre teoria e prática. São 
eles: "Transformação Social: um objeto pertinente à Psicologia Social?", de autoria de Bader B. Sawaia; "Processo de Produção Psicossocial de Conceitos: infância, juventude e cultura", de Adélia A. Souto de Oliveira e Alcimar E. R. Trancoso; "Os Impasses entre Acolhimento Institucional e o Direito à Convivência Familiar" de Maria Ignez C. Moreira; "O Inconsciente Sócio-histórico: aproximações de um conceito", de Lívia G. Santos e Inara B. Leão; “A Significação das Emoções no Processo de Organização Dramática do Psiquismo e de Constituição Social do Sujeito", de Lavínia L. S. Magiolino; "Sofrimento Ético-político: uma análise do estado da arte", de Fatima M. A. Bertini; e "Novas Possibilidades Metodológicas: a quebra dos paradigmas qualitativo e quantitativo em Psicologia", de Edna M. P. Kahhale e Elisa M. B. Esper.

O segundo bloco apresenta pesquisas e intervenções que analisam e/ou apresentam possibilidades de trabalho do psicólogo no campo das organizações coletivas e das políticas públicas e sociais. A preocupação central de todos é a compreensão dos processos de servidão e resistência dos que sofrem a opressão, para refletir sobre experiências singulares e coletivas voltadas a luta contra ameaças éticopolíticas, e para elaborar referências psicossociais à análise crítica de políticas sociais. Quatro temas são priorizados: arte, saúde, trabalho e políticas de assistência social. A arte é analisada na sua dimensão revolucionária/catártica, como "técnica social das emoções" como fala Vigotski. No tema saúde, as pesquisas partem de uma concepção ampliada do tema - saúde ético-política- para analisar a relação trabalho/ capital em sua manifestação no atendimento á saúde do trabalhador e, também, no contexto do SUS. São eles: "Subjetivação, Criação e Produção Audiovisual: uma experiência em torno de um espetáculo musical", de Kátia Maheirie, André L. Strappazzon, Flora L. B. Muller, Daniela S. Mayorca e Fábio R. Barreto; "Jovens Trabalhadoras e o Sofrimento Éticopolítico", de Maria Dionísia do A. Dias; "Atuação dos Psicólogos nos CRAS do Interior do RN”, de Isabel F. de Oliveira, Nívia L. de A. Oliveira, Marília N. C. do Nascimento, Rafaella L. Araújo, Fellipe Coelho-Lima e Keyla M. de O. Amorim; e "Participação Social e a Potência do Agente Comunitário de Saúde", de Carlos R. Castro e Silva, Rosilda Mendes, Ramiz C. P. de Moraes, Danilo de M. Anhas e Karina R. M. Rosa.

Encerramos este número com a tradução do artigo de Yves Clot intitulado Vygotsky: consciousness as connection. O ensaio apresenta uma discussão de textos de Vygotski traduzidos para o francês no livro Conscience, Inconscient, Émotions, em que a consciência aparece como um trabalho de conexão, sempre sujeito à desconexão.

Por fim, apresentamos a resenha intitulada "Reflexões sobre a Idéia de Comunismo", de autoria de Cécile D. Zozzoli, Luiz do N. Carvalho e Maria Helena de M. Coelho, acerca da obra de compilação de Analia Hounie, intitulada "Sobre la Idea del Comunismo", publicada pela Editora Paidós.

Desejamos a todos uma excelente leitura!

\author{
Profa. Dra. Bader Burihan Sawaia \\ Pontifícia Universidade Católica de São Paulo, \\ São Paulo/SP, Brasil \\ Profa. Dra. Kátia Maheirie \\ Universidade Federal de Santa Catarina, \\ Florianópolis/SC, Brasil
}

\section{Notas}

\footnotetext{
Vigotski refere-se aos Manuscritos economia y filosófico de 1844, Alianza Editorial, Madrid, 1984, p. 151.

2 Zavershneva- the Way to freedom Journal of Russian and East European psychology, vol.48, n 1 , ja-feb,2010, pp.61-90
} 